\title{
THE USE OF GAMES IN TEACHING MATHEMATICS AT HIGH SCHOOLS
}

\author{
Cuong Tran ${ }^{1,+}$, \\ Tram Hoang Ngoc Nguyen ${ }^{2}$, \\ Van Thu Trinh ${ }^{3}$
}

\section{Article History}

Received: January 07, 2020

Accepted: February 02, 2020

Published: March 30, 2020

\section{Keywords \\ Mathematical learning, mathematical game, educational game, mathematics teaching}

\author{
${ }^{1}$ Hanoi National University of Education, Vietnam; \\ ${ }^{2}$ The Olympia Schools, Hanoi, Vietnam; \\ ${ }^{3}$ Hoa Binh La Trobe School, Hanoi, Vietnam \\ ${ }^{+}$Corresponding author •Email: trancuong@hnue.edu.vn
}

\section{INTRODUCTION}

Developing students' learning competence has long been an integral component in educational innovation in general and Mathematics Education in particular. As learning competence can only be formed, developed, manifested and evaluated through learning activities, it is essential to develop new and diverse types of activities associated with the content of Mathematics.

Games in teaching have long been viewed as important educational tools with a long-standing history. According to Vankúš (2005), in ancient Greece, both Plato (427-347 BC) and Aristotle (384-322 BC) believed that the main method of education for children from 3 to 7 years old were games. When the first school in Europe came along with the first Roman republic, called Ludi (meaning games in English), people were only interested in motor games to develop the physical health for learners. In Europe, in the late Middle Ages, although the main educating methods were rigid discipline and learning by heart, and toys and the use of games were generally prohibited, it had been in continuous development and played a key role in children's maturity.

The purpose of the article is to seek a theoretical framework to describe the concept as well as to affirm the basis and pedagogical potential of games used in teaching Mathematics, then create a convenient library of teaching games for colleagues to put into application in high schools.

\section{LITERATURE REVIEW}

\subsection{Teaching games in Europe after the Middle Ages}

Also according to Vankús (2005), up to the Renaissance in Europe, the movement of restoring the cultural, scientific and educational light that was turned off by the ancient Greek civilization emerged. J.A. Comenius (15921670), in agreement with Plato-Aristotle, continued to emphasize i) the games in education were important and useful because of their relevance and impact on children's interests. The method of learning by playing (Ludus) was named and described carefully by the author in School of Infancy, Ludus \& Magna (1630) showed that ii) the emphasis on the importance of group games help children develop social skills, iii) games are the preparation for future work for children and iv) it's needed to lead children to change from spontaneous playing activities to internal working activities and v) educational games need rules and instructions.

Instead of focusing only on intellectual development, fostering and developing both physical and cognitive development was a priority; linguistics, formalism or rigid disciplines in medieval schools were abolished. Scholars always required that teaching had to be more dynamic and students learned more actively and learned towards reality. Using games in teaching, therefore, was the dominant choice at this period.

\subsection{Teaching games in the Golden Era of mathematics}

The golden era in mathematical history is the period of classical advanced mathematics (seventeenth - eighteenth century) with blossoming, simultaneous and brilliant achievements. At the same time, educators also achieve many important results. J. Lock (1632-1704) initiated the concept of Humanistic Opinion about Education while studying 
from theory to practice of learning tasks for students. Teaching should be completely natural, not forced, therefore, using games with letters and pictures to help children learn to read and write was necessary.

Following the concept of Humanistic Opinion about Education, J.J. Rousseau (1712-1778) was the first person to propose a restriction on school-age for students: - the children go to school to "work" from about 6-7 years old, the time before is "childhood", "playing age", the children under 6 years old must have right to play; methods such as learning by heart and stuffing one's head is obsolescent; - knowledge and method must come as naturally as possible, respective of age and individualism of children, or; - education is basically about having children observe, think and experience so; - playing is the best activity that a child must learn.

J.H. Pestalozzi (1746-1827) and F.W. Fröbel (1782-1852) believed that it is necessary to systematically use real games to realize educational goals. Real games may help children develop more comprehensively. It is Fröbel who was considered to be the creator of pre-school education method with six classical collections of toys help children to develop fully, from the sensory and motor apparatus, prepare vocabulary for reading and writing, calculating to many other rich abilities and skills in order to replicate the use of games in preschools.

Other authors also shared important theoretical points about games in education. According to F. Schiller (17591832), games are the place where an individual was released. H. Spencer (1820-1903) rightfully stated that game is a way to release excess energy from the "waiting" form to "useful" form. K. Groos (1862-1946) conceived that premature species of the fauna, including human, played to develop, prepare for growing up and maturity.

\subsection{Mathematical games in modern time}

The viewpoint that games should be widely used at a young age has been almost agreed, not raising controversy. Some theories have been systematically formed, becoming important foundations for Mathematical education since the middle of the twentieth century.

The tectonic theory of J. Piaget (1896-1980) was born when he began to observe cognitive development in his own children. Piaget considered 4 types of games including: "exercise game", "symbolic games", "game with rules" "constructive game" to confirm that games helped children develop motivation, emotion, intellect, and imagination.

Theory of the nearest development region of L.S. Vygotsky addressed the inherited continual development in the child's cognition, especially the link between thinking and language. Vygotsky reaffirmed that games were one of the most appropriate activities that contributed to the development of cognitive and thinking skills as well as emphasized and analyzed some of the important roles of children's social inclusion process.

\subsection{Studies on mathematics teaching games from the late twentieth century to the present time}

Whether games are suitable and should only be used at an early age is a very noticeable aspect of games in teaching Mathematics. Over the past decade, this issue has been further discussed, helping to reinforce confidence in the prospect of applying games at higher levels of primary education. Orim and Ekwueme (2011) confirmed the feasibility and effectiveness of applying games in teaching in secondary schools. Afari, Aldridge and Fraser (2012) demonstrated the effectiveness of games in teaching mathematics for high school age. Campos and Moreira (2016) conducted empirical studies that demonstrated the pedagogical potential of games for secondary school level.

\section{METHODS AND RESULTS}

\subsection{Research methods}

For data collection, the research methods include theoretical research with a focus on international comparison and Experience summary.

- Another dominant method used is theoretical research. Starting from the first 15 pages of search results with the phrase "teaching mathematics" + "playing games" on Google Scholar with reference bibliography, 10 publications that are most relevant for research purpose selected. Document of N.B. Nguyen (2017) was selected to compare the theory of teaching mathematics in Vietnam as it has been widely used in training from the university level in mathematics pedagogy - Theory and method of teaching Mathematics at the domestic main training institutions. We have compared and collated three main concepts namely Games for Teaching Mathematics, Mathematical Games and Games for Learning Mathematics, systematized the rich pedagogical benefits and potentials of the Games for teaching mathematics and synthesized some principles and notes when applying the Games for teaching Mathematics as well as presenting a common set of criteria for evaluating Games for Teaching.

- The method of experience summary used when we build and have been continuing to update and improve a library of games can be used in teaching Mathematics. Through our practical experience, exchanging ideas with some teachers of Mathematics who are interested in games and some monographs on mathematical games, we have 
learned and tried on a small scale and collected 26 games (with specific pedagogical potential analysis, use suggestion table in typical teaching situations or specific lessons and knowledge).

\subsection{Research results}

\subsubsection{Important terms}

- The mathematical organization, activities and games:

In order to give a suitable concept and classification system for the system of games for teaching Mathematics, the definition of activities and games can be considered from the concept of Mathematical organization. Wiersum (2012) synthesized and inherited the viewpoints of Bromme (1994), Chevallard (1997), Ball (1997), Jaworski (1998) or Gough (1998) to view mathematical organization as a system of potential actions and knowledge - which can be numerous and challenging, or even impossible, to fully and singly identify - packed in teaching program and content, such as subjects of Algebra, Trigonometry or Geometry.

When teaching a part of a large mathematical organization (such as a lesson, a chapter, a topic), teachers rely on knowledge, experience, belief, attitude, and other factors generally referred to as their pedagogical capacity to develop an organized system based on the system of actions and knowledge from the aforementioned "treasure" to create lesson plans that allow the operation of a scenario of actions for students to be applied in the classroom. The system created by a teacher is called a didactic organization.

Brousseau (2002) defines Didactical Games as an activity to bring joy and satisfaction to learners while realizing educational goals. They differ from common games in 3 factors: compulsion within the classroom (rather than voluntary as common games); the sense of "pedagogical goal"; subject to intervention, management from outside by teachers and rules of games depending on the certain pedagogical intention.

Oldfield (1991) defines Mathematical Games as an activity that contained a challenge when solving a task or struggling with a number of opponents, may also be a general task to be solved; governed by a set of rules based on a clear structure; required to have an end; aimed at a certain cognitive goal in teaching - learning mathematics. The author also listed up to 10 groups of Mathematical Games under their goals or pedagogical potential: 1) Puzzle-Type Games; 2) Games to Reinforce Concepts; 3) Games to Practice Skills; 4) Games to Stimulate Mathematical Discussion; 5) Games to Encourage the Use of Strategies - 6) Multicultural Games; 7) Mental Games \& Calculator Games; 8) Computer Games; 1k8) Collaborative Games; 9) Competitive Games; 10) Games for Emphasizing Underlying Mathematical Structures.

- Games for teaching Mathematics (GFTMs): By connecting the ideas and presentations of the above authors, it is recommended that the term Games for teaching Mathematics be used as a system of activities designed, controlled and directed to teaching goal by teachers in which all students must participate (individually or in a collaborative group), overcome challenges (opponents) by taking calculating actions that follow certain rules to win.

As GFTMs can be used in other subjects, they can be classified into two groups corresponding to their application (although there are some cases that are not easy to make clear): - Games for learning Mathematics are ones used for teaching mathematics in which mathematical knowledge often appears explicitly in the rules of a game. Teachers can incorporate knowledge of other subjects into Maths challenges without changing the teaching goal of the game. Games for learning Mathematics can be used in addition to Mathematics (Multicultural games, television games, and other types of interactive ones), allowing teachers to revise the rules of the games by incorporating mathematical knowledge. Democratic flower pick-up, knowledge competition, "magic hat" are typical examples of games of this group; - Mathematical Game are games for teaching Mathematics in which some specific mathematical knowledge is generally hidden in actions, reactions, strategies of players rather than stated explicitly in the rules of the games. In this way, they are more specific to Mathematics with a narrower application area by expressing the meaning of certain mathematical knowledge. They are close to basic situations of knowledge, from the perspective of the case theory (e.g., Gomoku, mandarin square capturing and Stone pick-up).

\subsubsection{Pedagogical potential of Mathematical Games}

From the perspective of recent international publications, the benefits of Games for teaching Mathematics have been confirmed and summarized in many works on mathematical education. Davies (1995) evaluated Games for teaching Mathematics as follows: - Allow to apply mathematical skills in meaningful situations; - Create positive learning motivation; - Improve the attitude in a positive direction for learning Mathematics; - Facilitate diversification of learning strategies; - Favorable for teaching in differentiated manner; - Favorable for the process of renewing the 
examination, evaluation, especially process evaluation; - Expand learning space outside the classroom; - Enhance and activate independent activities.

Shaftel et al. (2005), when discussing Mathematical Games for adolescents, added more specific benefits such as - Help to gain immediate feedbacks; - Strengthen manipulation with teaching facilities in problem-solving; - Help connect different areas of knowledge in Mathematics; - Promote mathematical argument.

Campos \& Moreira (2016) considered Games a resource to organize learning activities for secondary school students in Portugal. Based on elaborate theoretical research, in addition to the viewpoints that coincide with Davies \& Shaftel, notably deeper and more generalized ideas and implicit intents could be expressed through the Games for teaching Mathematics such as: - Realize the thought of Learning by doing; - Help transform the educational process into a self-educating process; - Help create a friendly learning environment, bring happiness to children, learning and having fun; - Strengthen practical mathematical education; - Facilitate the development of problem-solving capacity and mathematical thinking development.

Based on an experimental study using Jeopardy game organized for 90 high school students in Abu Dhabi - UAE, Afari et al. (2012) tested most of the advantages to come to the conclusion: the Jeopardy game showed a positive improvement in the Mathematics learning environment and attitude of students towards Mathematics. From the above publications, it can be seen that the interested international scholars have greatly appreciated and thoroughly found out the studies from theory to elaborate experiments on the pedagogical potential of GFTM. However, the difficult point to follow and to apply to the given arguments is that the systematization is still relatively loose, at least approaches to the process of teaching Mathematics in the traditional direction have been prevailing in Vietnam.

Comparison with traditional teaching theory, it is clear that the use of games to express important ideas facilitates the teaching process, including putting learners into the role of subject of learning activities (independent or cooperative); install knowledge in situations with pedagogical intent; focus on teaching the study and teaching selfstudy and teaching the assessment and self-assessment; create and exploit teaching facilities, especially information and communications technology; create optimism in learning based on labor and achievements of learners; define a new role of teacher acting as a person who designs, trusts, controls and institutionalizes. Using appropriate teaching games will serve the pedagogic intents as follows:

- Elicit positive learning motivation, form beliefs and positive attitudes with Mathematics: Learning motive is one of four basic components of teaching method, the theory of teaching Mathematics emphasizes two main sources of materials from practice and from internal Mathematics, 03 phases of beginning, intermediate, ending and many specific measures such as meeting the need of eliminating a restriction, directing towards convenience, rationalizing work, correcting a concept, looking forward to completeness - systematization, overcoming problems, generalizing, analogizing, and finding dependent relation.

- Develop learning situations. In problem-discovery and problem-solving teaching types, problems eliciting situations are created with different levels of difficulties of cognition, eliciting the need for cognition and instilling belief in self-ability are the main goals. The game of "Filling up the plane" is a good example of how a game creates a situation to help students become aware of the sum of angles in a polygon.

- Develop linguistic competence: Language in teaching and learning mathematics includes main components such as natural language (speaking and writing), logical elements and terminology - mathematical symbols. For example, in the game of "Guessing Teammate Ideas", players are not allowed to directly use the mathematical keywords given by the teacher but must use all their linguistic skills to "describe" the teammates what those keywords are.

- Conduct cooperative teaching: A team with effective cooperation needs to elicit the teamwork motive at a maximum level, the dependency among members is positive, clear in assigning and taking responsibilities, promote interaction, develop teamwork skill and have a self-assessment of the performance of individuals and team. The competitive games for teaching mathematics for teams and with replay are highly likely to become effective cooperative teaching phases.

- Strengthen skills to apply mathematical knowledge: If, in the traditional classroom framework, mathematical knowledge applied primarily at the first two levels is in internal Mathematics (for example to solve exercises) and inter-subject level (still in some practical, inter-subject exercises), many mathematical games require and show students immediately the third level of application in reality. When competing to solve a Sudoku board, it is time for students to apply (whether accidentally or not) clauses (if ... then ...), carry out multiple phases of case classification and used the crossing of the collections. 
- Perform the task of developing intellectual capacity: The task of developing intellectual capacity in Mathematics has many aspects that can be performed in various mathematical games: from forming and developing logical thinking - accurate language (games of keyword description), developing the ability to guess - imagine (3dimensional puzzles), train basic intellectual activities to facilitating sustainable intellectual qualities such as flexibility, creativity, independence, criticism, and other higher-order skills, and fostering common types of thinking such as creative thinking (game of "I'm different"), algorithmic thinking (game of "Hanoi Tower"), functional thinking (game of "thought reading machine") and critical thinking (game of "Finding mistakes").

- Contribute to innovation, inspection, and evaluation: Evaluation is the process of forming statements, judgments about work result, based on the analysis of the obtained information, compared with the goals and criteria set out in order to give appropriate decisions to improve the situation and adjust to improve the work performance and quality. 3.2.3. Notes when using mathematical games

Although there are many advantages, like any other trends, methods, techniques, it is essential not to abuse games in teaching Maths. The effectiveness and value of a game in teaching mathematics can be assessed through the following 7 main criteria: 1) Creating a comfortable, interesting and attractive atmosphere; 2) Attract students to participate; 3) Creating competition, fairness, cooperation among students, between students and teachers; 4) Easyto-understand rules; 5) Flexible, able to exploit and expand games with other mathematical contents; 6) Naturally, less likely to feel like carrying out a task at school; 7) Easy to store information, but does not require too sophisticated support facilities (Vankúš, 2005).

As suggested and proposed by Wiersum (2012), the GFTMs should: i) be suitable for the playing objects (age, gender, quantity, physiological demand), venue and time of play to ensure education; ii) be orientated towards learning and lesson content, not considered as an option to "kill time"; iii) limit factors reducing interest and concentration (such as waiting too long for turn or an overcrowded team); iv) include element of luck or easy parts for students with weak learning capacity; v) not be too competitive to intrigue students to "beat in a bad loser manner"; vi) have an easy-to-understand game rules (with a priority to be more mathematically diverse more than troublesome and complicated in rules); vii) carefully prepare playing tools (if any); viii) controlled by a proficient, experienced and practicing controller; ix) include a formalization phase after playing; $\mathrm{x}$ ) include a mechanism to encourage students to adjust, create new games by their own, try on outside the classroom.

\subsubsection{Examples of GTFMs applicable in classes of Mathematics}

There are many games for teaching mathematics that can be included in the classroom. There are 26 games for teaching Mathematics ( 9 mathematical games, 17 games for learning mathematics) that we have discovered and tested (the list of these games can be found in http://bit.ly/26TroChoi-CTV). Below are suggested GFTMs applicable in classrooms of Mathematics:

Game 1 (Logic Quiz): Teachers gives questions/riddles and students will answer the questions/ riddles individually or in groups.

Teacher-to-be potentials: This seemingly easy game intrigues students to solve quizzes, the process of which facilitates learners' critical thinking and analyzing skills, and enhances learners' language proficiency.

Examples of quizzes/ riddles:

Riddle 1: A man has to take a wolf, a goat, and some cabbage across a river. His rowboat has enough room for the man plus either the wolf or the goat or the cabbage. If he takes the cabbage with him, the wolf will eat the goat. If he takes the wolf, the goat will eat the cabbage. Only when the man is present are the goat and the cabbage safe from their enemies. All the same, the man carries wolf, goat, and cabbage across the river. How?

Solution: The wolf does not eat cabbage, so the crossing can start with the goat. The man leaves the goat and returns, puts the cabbage in the boat and takes it across. On the other bank, he leaves the cabbage but takes the goat. He leaves the goat on the first bank and takes the wolf across. He leaves the cabbage with the wolf and rows back alone. He takes the goat across.

Riddle 2: A tourist is at an intersection. One way is the Village of Lies and the other way is the Village of Truth. Villagers of Lies always lie and villagers of Truth citizens always tell the truth. A villager of one of the villages is at the intersection. What is a question you could ask them to find the way to the Village of Truth?

Solution: The tourist can ask villager "In which of these two directions do you live?" No matter which village the person is from, they will point toward the Village of Truth. This is because a citizen of the Village of Lies will lie and point to the Village of Truth, and a villager from the Village of Truth will truthfully point to the Village of Truth. 
Game 2: There are two participants in this game. Each student will take turn writing a natural number. The very first person to write may start with number 1 or 2 . The next person will write another number that the opponent has just written plus 1 or 2 . Whoever writes to 20 wins.

After many rounds, students will realize whoever writes number 17 first wins. Then students continue to realize whoever writes number 14 will be the winner. Students will gradually discover that the number sequence that the previous person need to write to ensure the winning will be $2,5,8,11,14,17,20$. The above situation is designed to help students understand the meaning of residual division.

\section{DISCUSSION AND CONCLUSION}

The theoretical framework shows that the use of mathematical games can be divided into two groups: mathematical games and games for learning mathematics, a special type of learning activity that has been used throughout the long history of Mathematical education and used so far.

There are many games for teaching mathematics that can be included in the classroom, at http://bit.ly/26TroChoiCTV, there is our printout of the library of GOTM - version 01. There are 26 games for teaching Mathematics (9 mathematical games, 17 games for learning mathematics) that we have discovered and tested. Applying games for teaching Mathematics at all three levels of education, as well as incorporating such games into training and professional development programs for teachers, proves feasible, effective, backed by a sound scientific ground. In this article, we include a compilation of teaching games with a detailed description of goals, pedagogical potentials, instructions for use or elaborate experimenting of a (some) game(s) for specific situations and objects can be attractive studies for interested colleagues. The documents of Krulik (2016), Gardner (1995) or Eiss (1998) are very useful references.

\section{REFERENCES}

Aldridge S. \& Badham V. (1993). Beyond Just a Game. Pamphlet Number 21, Primary Mathematics Association. Davies, B. (1995). The role of games in mathematics. Square One, 5(2), 7-17.

Ernest Afari, Jim M. Aldridge \& Barry J. Fraser (2012). Effectiveness of using games in tertiary level mathematics classrooms. International Journal of Science and Mathematics Education, 10, 1369-1392.

Guy Brousseau (2002). Theory of Didactical Situations in Mathematics: Didactique des Mathématiques 1970-1990. Mathematics Education Library.

Harry Edwin Eiss (1988). Dictionary of Mathematical games, puzzles, and amusements. Greenwood Press.

Helena Campos \& Rute Moreira (2016). Games as an educational resource in the teaching and learning of mathematics: an educational experiment in Portuguese middle schools. International Journal of Mathematical Education in Science and Technology, 47(3), 463-474.

John Gough (1999). Playing (mathematics) games: When is a game not a game?. Australian Primary Mathematics Classroom, 4(2), 12-17.

Julia Shaftel, Lisa Pass \& Shawn Schnabel (2005). Math games for adolescent. Teaching Exceptional Children, 37(3), 25-30.

Krulik S. \& Posamentier A. S. (2016). Strategy Games to Enhance Problem-Solving Ability in Mathematics. In series Problem Solving in Mathematics and Beyond: Volume 5, World Scientific Publishing.

Martin Gardner (1995). New Mathematical Diversions, in Spectrum Series. The Mathematical Association of America.

Nguyen Ba Kim (2017). Methods of mathematics teaching. University of Education Publishing House.

Orim R. E. \& Ekwueme C. O. (2011). The roles of games in teaching and learning of mathematics in junior secondary schools. Global Journal of Educational Research, 10(2), 121-124.

Peter Vankúš (2005). History and present of didactical games as a method of mathematics' teaching. Acta Didactica Universitatis Comenianae, 5, 53-68.

Thomas Armstrong (2014). Multiple Intelligences in the Classroom (Translator: Le Quang Long). Vietnam Educational Publishing House.

Wiersum E. G. (2012). Teaching and learning mathematics through games and activities. Acta Electrotechnica et Informatica, 12(3), 23-26. 